\title{
Mediterranean cyclone characteristics related to precipitation occurrence in Crete, Greece
}

\author{
V. Iordanidou ${ }^{1}$, A. G. Koutroulis ${ }^{1}$, and I. K. Tsanis ${ }^{1,2}$ \\ ${ }^{1}$ Department of Environmental Engineering, Technical University of Crete, GR73100 Chania, Greece \\ ${ }^{2}$ Department of Civil Engineering, McMaster University, Hamilton, ON, L8S 4L7, Canada \\ Correspondence to: I. K. Tsanis (tsanis@hydromech.gr)
}

Received: 30 May 2014 - Published in Nat. Hazards Earth Syst. Sci. Discuss.: 30 September 2014

Revised: 11 June 2015 - Accepted: 31 July 2015 - Published: 13 August 2015

\begin{abstract}
The characteristics of the cyclone tracks that caused precipitation events of variable intensity for the period 1979-2011 over the island of Crete are presented. The data set used for cyclone identification is the $0.5^{\circ} \times 0.5^{\circ}$, 30 years European Centre for Medium-Range Weather Forecasts (ECMWF) ERA-Interim mean sea-level pressure. Cyclone characteristics are calculated with the aid of the Melbourne University algorithm (MS scheme). Daily precipitation data from a dense gauging network over the island of Crete are also used for the classification of the precipitation events in terms of rain accumulation (intensity). Daily precipitation is classified in three categories and the associated cyclones are chosen according to their distance from Crete island. The seasonal and annual cycle of the physical characteristics of the cyclone tracks are investigated with respect to the cyclones' relative position to the island of Crete. It was found that cyclones affecting Crete most frequently approach from the western side of the island and the actual cyclone centers associated with precipitation events are usually located northwest and southeast of the Crete domain. Cycloneinduced rainfall increases in function to cyclones' depth, radius and propagation velocity increase as well as cyclones' pressure decrease. Spring cyclones that affect Crete with rainfall present lower pressures and higher cyclone propagation velocity in contrast to the ones associated with winter and autumn precipitation events. The examination of the relation between cyclone characteristics and precipitation occurrence provides valuable information related to forecasting potential and management of the water resources and the rainfall extremes.
\end{abstract}

\section{Introduction}

In the Mediterranean region, a great number of precipitation events are triggered by cyclonic circulation patterns (Jansa et al., 2001b; Lionello et al., 2006). The extratropical cyclonic circulation patterns are frequently associated with wind, heavy precipitation and changes in temperature (Ulbrich et al., 2003), generating high risk situations such as flash floods and large-scale floods with significant impacts on human life and built environment. Particularly in the Mediterranean region, flood events are highly related to specific cyclone pathways (Jansa et al., 2001a). Mediterranean cyclones are responsible for the majority of extreme weather phenomena, governing the time of occurrence as well as the magnitude of their extreme values (Lionello et al., 2006).

The identification, tracking and evaluation of cyclone characteristics has been the subject of much research, providing diverse results even when the examined data sets are identical (Neu et al., 2013; Ulbrich et al., 2009). In an effort towards objective analysis, automated systems and algorithms have been developed for the identification and tracking of cyclones as well as the extraction of their characteristics based on spatio-temporal data sets of mean sea-level pressure (MSLP). Neu et al. (2013), after comparing 15 detection and tracking schemes (including the MS scheme) on a common cyclonic data set, found that there are differences in the number of cyclones, their lifetime, frequency as well as their characteristics, such as depth and speed.

The state-of-the-art cyclone finding and tracking scheme (MS scheme) developed at the Melbourne University, Australia (Murray and Simmonds, 1991), has been widely used for the definition of closed and open systems on reanalysis data and has proven to be effective, not only for the genera- 
tion of an objective climatology, but also for the assessment of individual tracks in an inland sea with complex shoreline topography, such as the Mediterranean. Evaluation of the MS scheme has demonstrated its efficiency for both the detection of individual tracks as well as its effectiveness in providing cyclone climatologies (Flocas et al., 2010; Leonard et al., 1999; Simmonds and Murray, 1999). While the MS scheme is capable of identifying cyclones in a range of locations with different characteristics, it has previously been employed in the eastern Mediterranean for the identification and analysis of cyclones (Flocas et al., 2010) and explosive cyclones' characteristics (Kouroutzoglou et al., 2011a).

Many studies have thoroughly investigated various characteristics of Mediterranean cyclones including cyclogenesis, temporal variability, location and dynamics. Trigo et al. (1999) performed cyclone detection and tracking using the criterion of geopotential height in order to identify cyclogenesis and cyclolysis regions, as well as cyclone characteristics including duration and intensity in the Mediterranean region. Their findings include strong cyclogenesis activity in the Gulf of Genoa region, south of the Atlas Mountains and in the Middle East, as well as high frequency and unexpectedly high intensity of spring lows over North Africa. An evaluation of the structure and variability of cyclones affecting the eastern Mediterranean region for the 1962-2001 40 year period was performed by Flocas et al. (2010), using the MS scheme, verifying considerable intermonthly variations for eastern Mediterranean track density. For the same period and using the same scheme, (Kouroutzoglou et al., 2011a) investigated the characteristics and behavior of Mediterranean explosive cyclones as well as their vertical structure (Kouroutzoglou et al., 2012). Furthermore, Maheras et al. (2001) and Bartholy et al. (2008) identified and analyzed the synopticscale cyclones that occurred in the Mediterranean region for the periods 1958-1997 and 1957-2002, respectively, focusing on the frequency of occurrence, location, genesis and seasonal variations.

Except for cyclone parameters and tracks, many studies have investigated the association of cyclones with precipitation. According to Flaounas et al. (2014) who examined the 200 most intense cyclones over a 20 year period, the strongest rainfall is observed close to the center of the cyclone, suggesting relative weakness of the Mediterranean cyclones compared to cyclones formed over the main oceans. Jansa et al. (2001) investigated the simultaneous occurrence of heavy precipitation and cyclonic centers for the western Mediterranean using data sets from relative databases. For the period 1958-2000, Karagiannidis et al. (2009) examined extreme precipitation events in Europe triggered by cyclones, focusing on the characteristics and trends of rain events rather than the features of the causative cyclones. Hawcroft et al. (2012) evaluated the contribution of midlatitude cyclones to the precipitation of the Northern Hemisphere, showing association of precipitation with cyclones by over $70 \%$ in two different reanalysis data sets. Similarly,
Catto et al. (2012) quantified the association of precipitation to the different categories of frontal systems and found, using information of global precipitation and reanalysis data, that up to $90 \%$ of rainfall is due to cold and warm fronts. Also, Miglietta et al. (2013) found that it is before the mature cyclone phase when the most intense convective activity and rainfall happens. In the same manner, Claud et al. (2010) stated that it is in the early stage of Mediterranean hurricanes (medicanes) that significant precipitation occurs.

The majority of extreme rain events in the Mediterranean region are associated with cyclones and rarely develop under different circumstances such as small convective cells ( $\mathrm{Li}-$ onello et al., 2006). Investigating the characteristics of the cyclones causing extreme precipitation is of great interest for the Mediterranean area, where the relatively small frequency of adverse weather and extreme events creates a false sense of safety that results many times in more damage and severe socio-economic consequences (Lionello et al., 2006). In this context, Jansa et al. (2001) investigated the cyclone-rain relationship considering the extreme cases of precipitation with heavy rain $\left(>60 \mathrm{~mm} \mathrm{day}^{-1}\right)$ and heaviest rain events $\left(>100 \mathrm{~mm} \mathrm{day}^{-1}\right.$ ) for different Mediterranean regions. Also, Tsanis et al. (2012) performed an analysis of cyclones associated with flood events, concentrating on the genesis, tracks and depth of those systems.

The goal of this study is to evaluate the characteristics of the cyclones related to precipitation events of specific accumulations in the island of Crete. Cyclone centers related to rainfall occurrence are identified and analyzed. Furthermore, the relationship between the intensity of the precipitation and both location (cyclone position) and quantitative characteristics (pressure, intensity, depth, radius and propagation velocity) of the cyclones is investigated. Here we make the hypothesis that a better understanding of the association of cyclonic characteristics and precipitation events will be helpful for early warning against extreme events that can potentially pose risk to life and property. The analysis presented in this paper aims towards a better evaluation of the atmospheric systems' characteristics for cyclones suspected to be associated with rain events in the island of Crete.

\section{Methodology and data sets}

\subsection{Methodology}

The main goal of this research is to reveal the statistics of the cyclones causing precipitation of specific intensity intervals. Statistical analysis is performed on the cyclones, matched to defined rain categories. The origination, location and characteristics (pressure, intensity, depth, radius and propagation velocity) of those systems are distinguished and examined. The analysis is also extended concerning seasonality (winter, spring, autumn) of the events. 
Here we consider that event intensity can be assessed according to the amount of rainfall accumulated at a gauging station over an arbitrary amount of time. Events are classified into three intensity intervals (rain categories) with respect to the 50th, 95th and 99.5th percentiles of cumulative daily precipitation according to the empirical data distribution. Each percentile is estimated for every station and then the average of the corresponding percentiles of all the stations is used as a boundary for each rain category. The concept of choosing the specific percentiles is the statistical analysis of cyclones, associated with precipitation outside of the average pattern. In particular, the 99.5th percentile concerns extreme rain events over $100 \mathrm{~mm} \mathrm{day}^{-1}$ which, on average, affects a gauging station in Crete once in every 3.5 years (there is a different return period for every station). The percentiles for every gauging station are estimated after the exclusion of "dry" days (lower than $1 \mathrm{~mm}$ day $^{-1}$ ). We consider a rain event to have occurred if at least one of the stations has records of rain within the intervals of the rain categories, so that rain of different severity categories can be recorded on a daily basis.

The cyclone identification and tracking in this analysis is carried out with the aid of the Melbourne University cyclone finding and tracking scheme (MS scheme) which uses the quasi-Lagrangian perspective (Murray and Simmonds, 1991; Simmonds and Murray, 1999). A special characteristic of the scheme is its ability of defining closed and open systems, with the aid of both pressure and relative vorticity fields (Flocas et al., 2010; Leonard et al., 1999; Ulbrich et al., 2009). This is a great asset of the algorithm because using just the information of local minima can exclude certain types of systems and in contrast, vorticity maxima are not always connected to local pressure minima. The parameters of the cyclone tracks are retrieved from the MS scheme and include the cyclone pressure, radius, depth, intensity and propagation velocity.

Radius $R$ is defined as

$R^{2}=\frac{1}{N} \sum_{i=1}^{N} r_{i}^{2}$,

where $r_{i}$ is the distance of the radial line from the cyclone center to the points at which the Laplacian of the pressure is zero (at the edge of a cyclone) and $N$ is the number of the radial lines drawn for every $20^{\circ}$ (Lim and Simmonds, 2007; Murray and Simmonds, 1991).

The intensity of the cyclone is given by the Laplacian of the central pressure $\nabla^{2} P$ (Lim and Simmonds, 2007; Murray and Simmonds, 1991; Simmonds and Keay, 2000). The depth $D$ of the cyclone is defined as

$D=\frac{1}{4} R^{2} \nabla^{2} P$.

The depth of the cyclone represents the general influence of the cyclone in terms of intensity and scale as it is proportional to $\nabla^{2} P$ and $R$.
Finally, the propagation velocity of the cyclone is given by

$U=\sqrt{U_{\mathrm{E}}^{2}+U_{\mathrm{N}}^{2}}$,

where $U_{\mathrm{E}}$ is the eastward component of cyclone-steering velocity and $U_{\mathrm{N}}$ is the northward component of cyclonesteering velocity.

Regarding tracking algorithms, there are inconsistencies within the context of the estimation of the cyclone center and radius (Neu et al., 2013). Detailed distance measures, such as from the cyclone center to the gauging station can convey insufficient information when MSLP data set grid spacing is set at poor resolutions. Accordingly, this estimation of exact distances between the cyclone center and each gauging station could lead to the omission of rain events associated with the corresponding cyclone. Motivated by this, a method of spatial matching between cyclone appearance and precipitation events in the area of interest is proposed here. The simple measure of Euclidian distance between the cyclone center and a boundary surrounding the entire area of interest is considered appropriate to overcome uncertainties concerning cyclone exact position and size. In order to restrict the area of interest, a rectangle boundary enclosing it is defined. So, a cyclone is considered to be sufficiently close to Crete when its radius is greater than the cyclone's center Euclidian distance to the rectangle boundary surrounding the area of interest. For this approach to be accurate, it is necessary for the area of restriction to have dimensions comparable to the local cyclones' radius.

Another issue of interest is the temporal association of the cyclones to the precipitation events. The temporal synchronization of rain and cyclone recordings leads to a direct matching. However, the recordings of different data sets do not usually have temporal synchronization. In this context, if the rain data set has time intervals $\left[T_{1}, T_{2}\right]$ where $T_{1}, T_{2}$ are two consequent rain recordings, the cyclones responsible for event $T_{2}$ are those recorded within $\left[T_{1}, T_{2}\right]$. At this point, it has to be noted that when the exact time of the rain is not available (e.g., daily rain recordings) only an approximate simultaneity between cyclone occurrence and rain can be assumed. Thus, there is a possibility that the cyclone system/s considered as responsible for precipitation events are not actually triggering rain.

Finalizing the procedure, after the cyclones are matched to the defined rain events, resulting in the so-called "affecting" cyclones, their characteristics are evaluated.

\subsection{Data sets}

The data set used in this study for the identification of cyclone tracks involves analysis of MSLP data on a $0.5^{\circ} \times 0.5^{\circ}$ regular latitude-longitude grid at a 6-hourly temporal resolution for the period 1979-2011 as derived from the ERAInterim Reanalysis of ECMWF. The calibration scheme used in this study is equivalent to the one used by Flocas et al. 


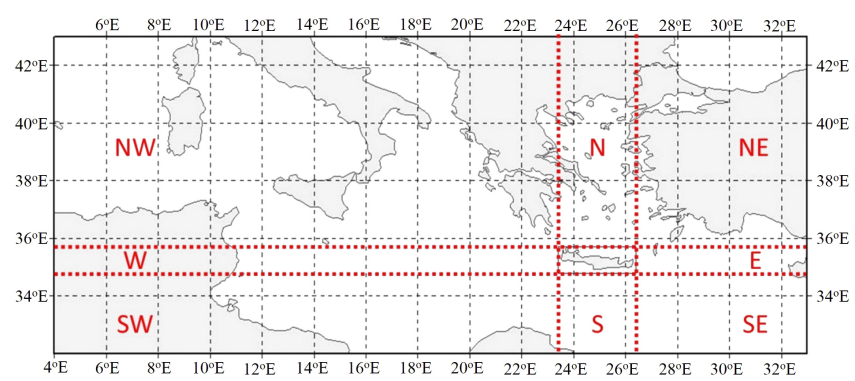

Figure 1. Location of study area and borders (red) of geographical sectors, corresponding to their relative position to the island of Crete.

Table 1. The rain categories according to the daily rainfall accumulation.

\begin{tabular}{ll}
\hline $\begin{array}{l}\text { Rain } \\
\text { category }\end{array}$ & $\begin{array}{l}\text { Rain amount } \\
\left(\mathrm{mm} \mathrm{day}^{-1}\right)\end{array}$ \\
\hline Mild & $10-50$ \\
Strong & $50-100$ \\
Heavy & $>100$ \\
\hline
\end{tabular}

(2010). Tracks in Mediterranean region have an average lifetime of $28 \mathrm{~h}$ when short-lived systems are excluded (Trigo et al., 1999). So, to be consistent with other studies (Bartholy et al., 2008; Flocas et al., 2010; Kouroutzoglou et al., 2011b; Lim and Simmonds, 2007; Murray and Simmonds, 1991; Neu et al., 2013; Simmonds and Murray, 1999) a minimum life span of $24 \mathrm{~h}$ is imposed on the tracks included in this analysis. In addition, short-lived cyclone systems lasting less than $24 \mathrm{~h}$ are not considered important as they provide less precipitation (Bartholy et al., 2008).

The study domain for the detection and identification of the cyclones includes part of the middle-eastern Mediterranean area and extends between $4-33^{\circ} \mathrm{E}$ and $32-43^{\circ} \mathrm{N}$. The domain of Crete was defined within the domain of 23.4$26.4^{\circ} \mathrm{E}$ and $34.8-35.7^{\circ} \mathrm{N}$. In Fig. 1 the study domain and Crete boundary are shown. The sectors of analysis are characterized as northwest $(\mathrm{NW})$, north $(\mathrm{N})$, northeast $(\mathrm{NE})$, southwest (SW), south (S), southeast (SE), west (W) and east (E), considering their relative position to the Crete domain.

Three types of intensity are defined for daily precipitation in Crete, summarized in Table 1. Figure 2 presents the 50th, 95th and 99.5th percentiles for the whole gauging network of Crete, spatially interpolated with the inverse distance weighting (IDW) method.

Accumulated precipitation is recorded at 06:00 UTC on a daily basis for every station, while the cyclone tracks are extracted at a temporal resolution of every $6 \mathrm{~h}$ at 00:00, 06:00, 12:00 and 18:00 UTC, according to the MSLP data set. So the tracks considered to be responsible for a specific precipitation event are checked for the date the rainfall was measured at 00:00 and 06:00 UTC and also for the previous day at

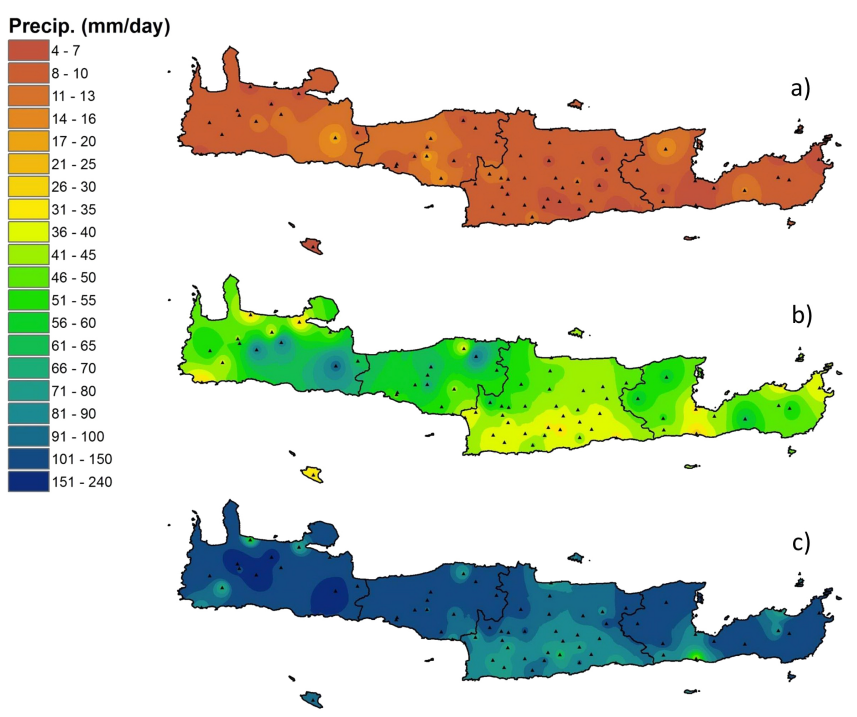

Figure 2. Spatially interpolated (IDW) daily precipitation fields for the (a) 50th percentile, (b) 95th percentile and (c) 99.5th percentile, based on records from 69 gauging stations.

18:00, 12:00 and 06:00 UTC in order to include every possible cyclone which could have caused the recorded precipitation in the analysis. This way, a day-long duration is checked for cyclone appearance for every rain recording.

\section{Study site}

This study is focused on the island of Crete which is located in the southern part of Greece. Crete is the largest island in Greece and one of the largest in the Mediterranean, with an area of $8265 \mathrm{~km}^{2}$, mean elevation of $482 \mathrm{~m}$, ranging from sea level to approximately $2450 \mathrm{~m}$, and an average slope of $228 \mathrm{~m} \mathrm{~km}^{-1}$. Crete has a subhumid Mediterranean climate, characterized by long, hot and dry summers and relatively humid and cold winters. As such, most annual rainfall occurs in winter and rarely during summer (Koutroulis et al., 2010). Also, the northwestern part of the island receives greater precipitation than the southeastern part (Chartzoulakis and Psarras, 2005; Koutroulis et al., 2010; Vrochidou and Tsanis, 2012). Precipitation in Crete varies between $440 \mathrm{~mm}^{-1} \mathrm{ear}^{-1}$ for lowland coastal areas and over $2000 \mathrm{~mm} \mathrm{year}^{-1}$ for mountainous areas such as Askifou upland in Chania (Koutroulis and Tsanis, 2010).

In the present study, precipitation characteristics are analyzed based on a data set of 69 daily gauging stations which are illustrated in Fig. 2. The WRDPC (Water Resources Department of the Prefecture of Crete) service is responsible for the compilation and quality of the daily precipitation records (Koutroulis et al., 2010). Out of the entire data set, 14 gauges recorded data for periods less than 10 years and 49 recorded data for more than 30 years. The temporal discontinuity of the rain recordings is of minor importance as the 


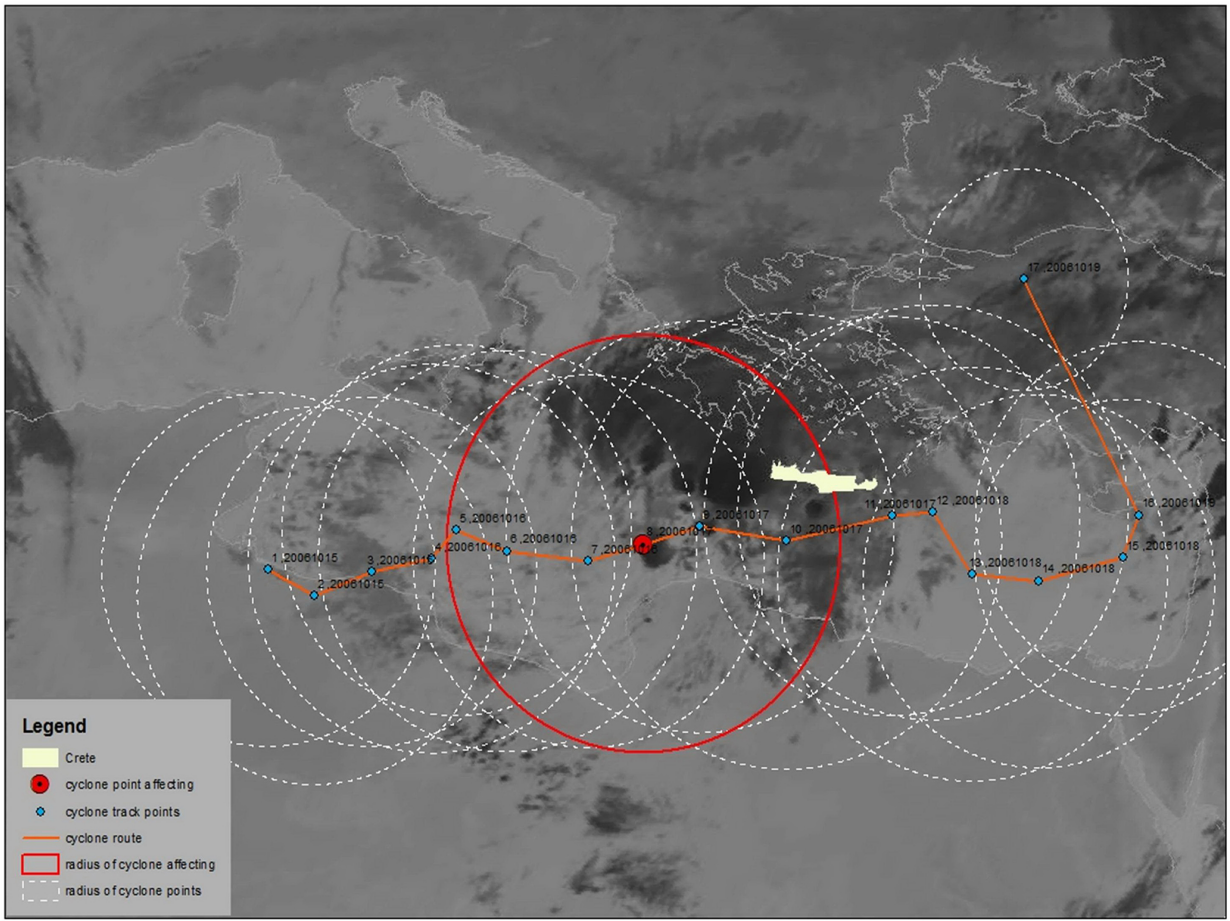

Figure 3. The track and radius of each track point of the cyclone which caused the flash flood in Almirida on 17 October 2006 . The background information is the infrared METEOSAT image at 00:00 UTC on 17 October 2006.

Table 2. The precipitation events in Crete per season for the period 1979-2011. The non-shaded columns contain the number of precipitation events and the shaded columns show the relative frequency $(\%)$ of simultaneity of cyclone and rain.

\begin{tabular}{|c|c|c|c|c|c|c|c|}
\hline & \multicolumn{2}{|c|}{ Mild rain } & \multicolumn{2}{|c|}{ Strong rain } & \multicolumn{2}{|c|}{ Heavy rain } & \multirow{2}{*}{$\begin{array}{c}\text { Mean } \\
\text { coincidence }\end{array}$} \\
\hline & Events & $\%$ & Events & $\%$ & Events & $\%$ & \\
\hline Annual & 3402 & 54 & 966 & 70 & 278 & 76 & 66 \\
\hline Autumn & 846 & 51 & 257 & 70 & 78 & 73 & 65 \\
\hline Winter & 1720 & 54 & 540 & 68 & 159 & 76 & 66 \\
\hline Spring & 760 & 59 & 156 & 75 & 37 & 81 & 72 \\
\hline
\end{tabular}

present analysis focuses on the coincidence of cyclonic appearance with precipitation events; in this case there should be at least one gauge station which has rain records. Also, approximately $85 \%$ of the gauge stations' records are found to be dry $\left(<1 \mathrm{~mm} \mathrm{day}^{-1}\right)$.

Characteristic flash flood events in Crete include those in the Giofyros basin on 13-14 January 1994 (Gaume et al., 2009; Koutroulis and Tsanis, 2010; Marchi et al., 2010) and in the Almirida basin on 17 October 2006 (Grillakis and Tsanis, 2010; Marchi et al., 2010; Tsanis et al., 2008, 2013), which have been thoroughly studied. Figure 3 presents an infrared METEOSAT snapshot at 00:00 UTC on 17 October 2006, corresponding to the accumulated water vapor of the atmospheric system, causing the flash flood event in the Almirida basin. The orange line shows the route of the cyclone passing through the blue points which correspond to the cyclone centers as estimated by the MS scheme. In the figure, white dashed circles correspond to the radius of the cyclone centers and red circle to the radius of the red cyclone center which is the cyclone evident on the METEOSAT image. MS scheme estimation of the cyclone is accurate, comparing the cyclone location and its radius to the actual phenomenon recorded in the METEOSAT image. The cyclone track has an eastward direction, and at 00:00 UTC on 17 October, centered at a southwest position in relation to Crete's bounded area, it starts precipitating in agreement with Grillakis and Tsanis (2010). 


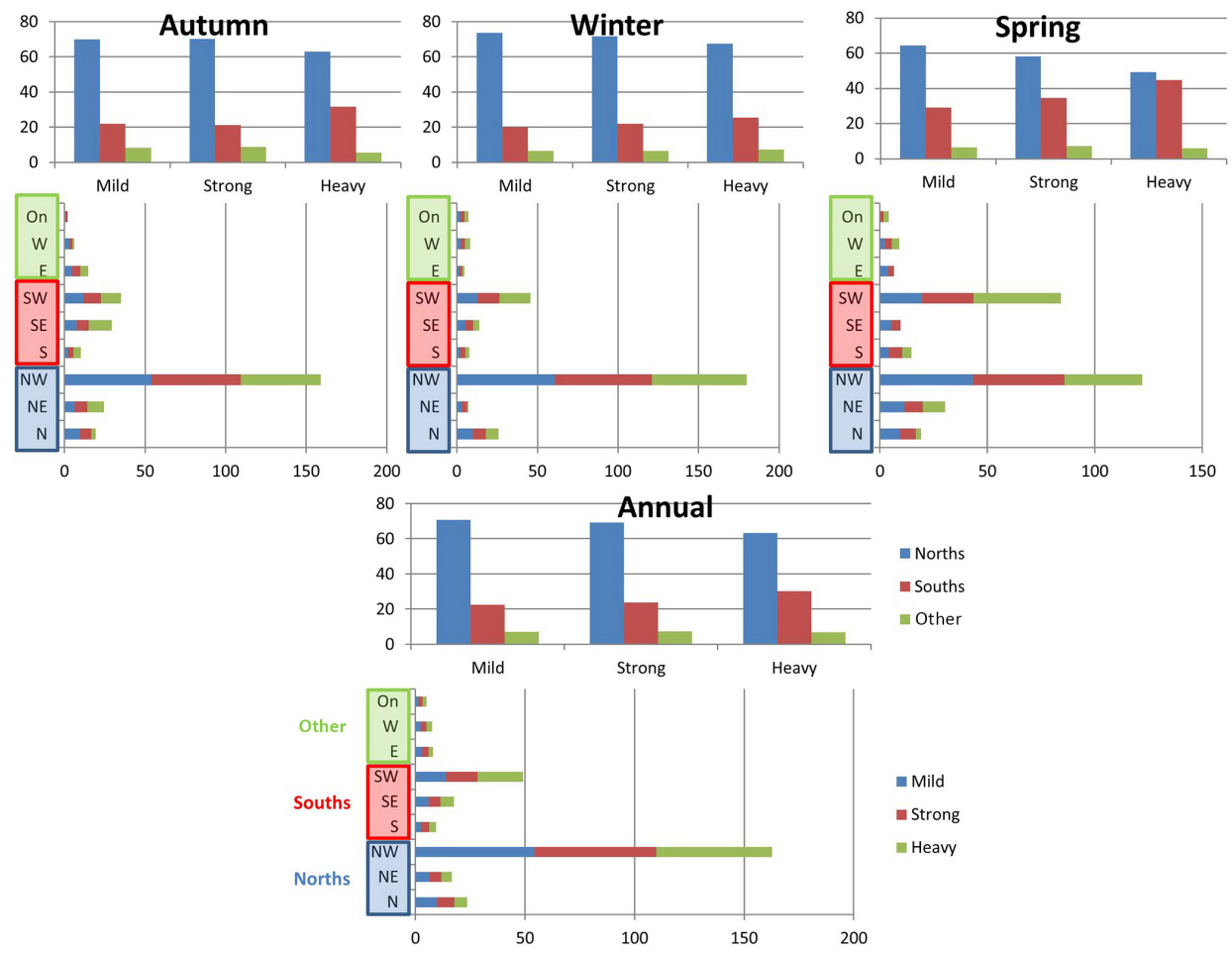

Figure 4. Annual and seasonal relative frequency (\%) of the origination of cyclones affecting Crete, 1979-2011. The stacked bar diagrams concern every sector and the simple bar diagrams are the grouped results for north (N, NE, NW), south (S, SE, SW) and the remaining (E, $\mathrm{W}$, On) sectors. On represents cyclones located within the Crete domain.

\section{Results}

\subsection{Cyclone-induced rainfall}

Most of the rain events occur in winter $(50 \%$ for mild rain, $>55 \%$ for strong and heavy rain), followed with great difference by autumn and spring, consistent with Koutroulis et al. (2010). Considering all the available gauge stations, an annual average of 110 mild rain, 30 strong rain and 10 heavy rain events occur at different locations in Crete. The number of precipitation events per intensity category and season for the period of analysis is presented in Table 2. In addition, the percentage of the events which could be triggered by cyclones are estimated, concerning the coincidence of precipitation and the appearance of "affecting" cyclones within a sufficiently close distance from Crete's boundary.

According to Table 2, mostly strong and heavy rainfall is caused by cyclones. As a matter of fact, $70 \%$ of the annual rain events for strong rain are likely to be related to cyclone activity and $76 \%$ of the annual rain events for heavy rain. In contrast, $54 \%$ of the annual rain events for mild rain might be triggered by a cyclone passage. Annually, $66 \%$ of the rainfall events in Crete are associated with a cyclone, in agreement with Catto et al. (2012) and Hawcroft et al. (2012) who found an approximately 60-70\% contribution of extratropical cyclones to precipitation north of $30^{\circ} \mathrm{N}$. Taking into consider- ation the seasonal results of Crete, it appears that for both strong and heavy events, rain-cyclone coincidence is greater in spring (up to $80 \%$ for heavy rain) followed by winter and autumn. The remaining precipitation events that are not found to be connected to cyclones are either local-scale lows that cannot be captured by the MS scheme or are provoked due to the complex Cretan land topography and orographic effects (Lionello et al., 2006; Naoum and Tsanis, 2003).

\subsection{Cyclones inducing rainfall over Crete: track analysis}

Most of the "affecting" cyclones originate northwest and southwest of Crete and they have southeast and northeast directions, respectively, for the majority of cases. Figures 4 and 5 show in detail the variability of the cyclones' origination and location for each of the sectors we have considered both seasonally and annually. There follows a comparison of the cyclone centers' relative frequencies within the sectors, taking into consideration that the areas of the sectors are not equal.

On an annual basis, approximately $70-80 \%$ of the cyclone centers originate northwest and southwest of Crete. More specifically, approximately $55 \%$ of the cyclones are generated northwest and about $15 \%$ southwest of Crete. 


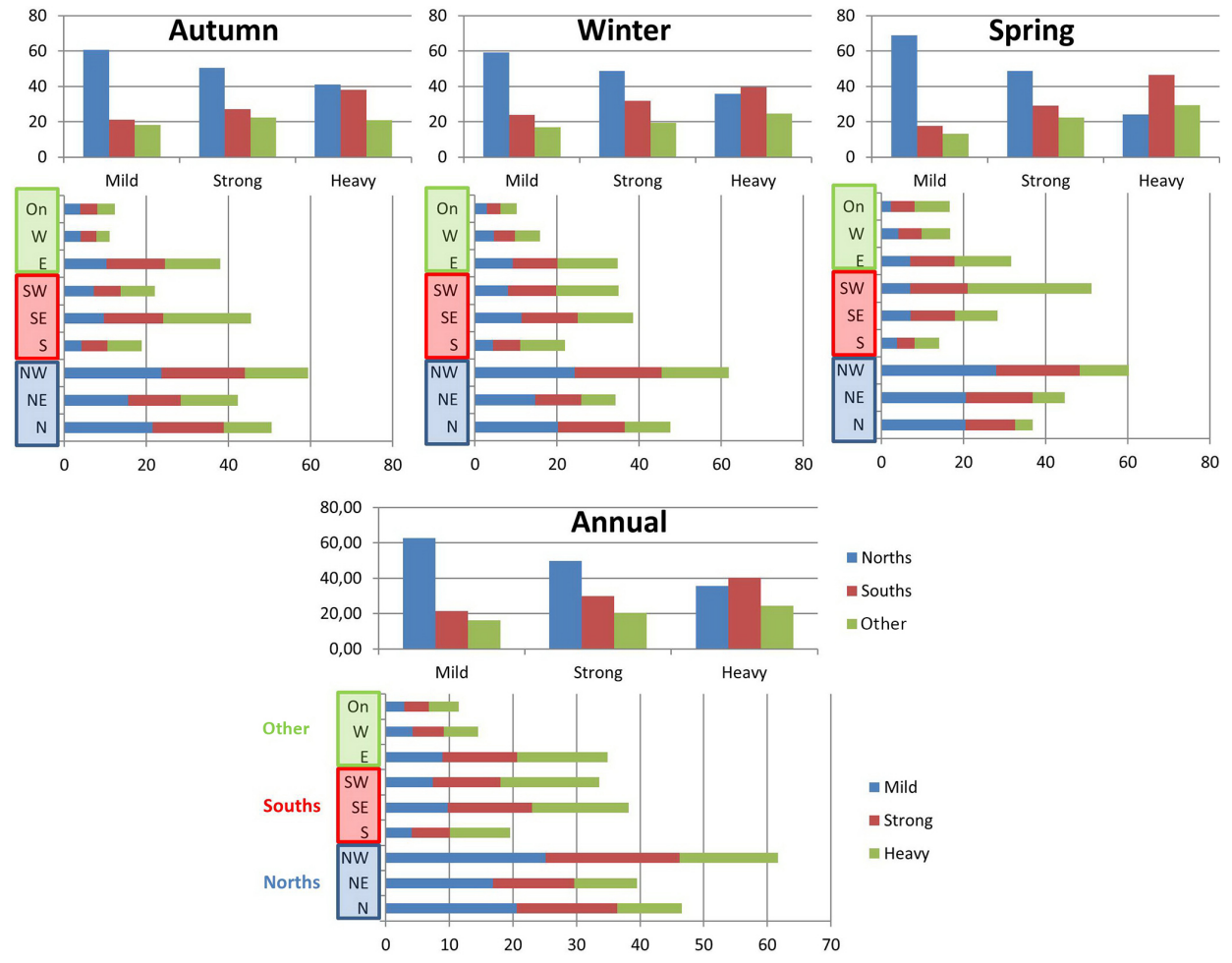

Figure 5. Annual and seasonal relative frequency (\%) of the position of cyclones affecting Crete, 1979-2011. The stacked bar diagrams concern every sector and the simple bar diagrams are the grouped results for north (N, NE, NW), south (S, SE, SW) and the remaining (E, $\mathrm{W}$, On) sectors. On represents cyclones located within the Crete domain.

Regarding seasonality, it can be observed that winter has the greatest percentage of northwest cyclones $(\sim 60 \%)$ and spring the least $(\sim 45 \%)$ while the exact opposite holds for the cyclones originating from southwest directions. Also, the more intense the precipitation, the greater the percentage of cyclones originating southwest compared to northwest. This holds for all seasons but it is more profound in spring where northwest cyclones reach to $40 \%$ of the total cyclones and southwest decrease to approximately $35 \%$. Both Flocas et al. (2010) and Trigo et al. (1999) agree that there is an observed increase of the North African tracks in spring compared to the other seasons in agreement to our findings. This difference between winter and spring is more profound for heavy rain events.

The positions of the cyclones causing precipitation events in Crete are presented in Fig. 5. For both mild and strong rain, the majority of the cyclones centers are located north of Crete, reaching approximately up to 60 and $50 \%$ of the total events, respectively. In comparison with mild rain, the cyclone centers located in the south become more frequent than the ones in the north when heavy rain occurs. Northwest and southeast sectors are those that principally contribute in the north and south directions respectively.

In the seasonal analysis, in all cases there are fewer north cyclone centers as precipitation gets more intense with a proportional increase of cyclone centers located south. The most profound example of this behavior is spring, where north cyclone centers decrease from $69 \%$ in mild rain cases down to $32 \%$ for heavy rain, and on the other hand south cyclone centers increase from 18 up to $47 \%$. In particular, southwest and northwest centers are the principal south and north cyclone centers in spring.

\subsection{Cyclones affecting Crete: characteristics' histograms}

A cyclone mechanism can be described by many parameters including its pressure, intensity, depth, radius and propagation velocity. These characteristics constitute measures of cyclonic systems' importance and influence (Simmonds and Keay, 2000).

The histograms of the values for these characteristics are presented in Fig. 6. The histograms concern the parameters of the cyclone centers which have a sufficiently close distance from the boundary we have defined for Crete. More specifically, according to their location, they potentially affect Crete judging from their distance from the defined boundary and their radius.

According to the respective histograms, the values of pressure and radius follow normal distributions. On the other hand, intensity, depth and propagation velocity values have left skewed distributions. More than $85 \%$ of the pressure val- 
Pressure Histogram

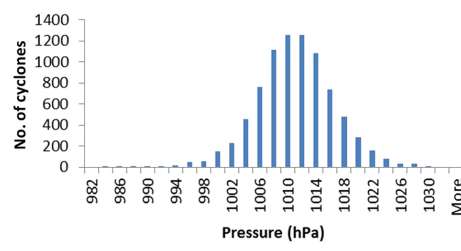

Depth Histogram

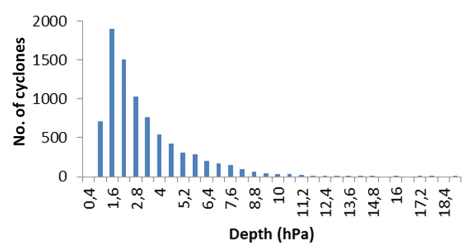

Intensity Histogram

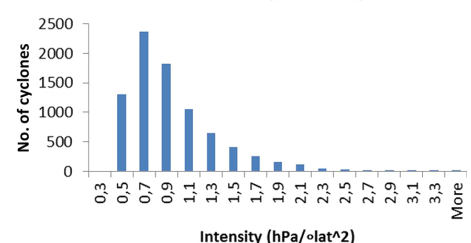

Radius Histogram

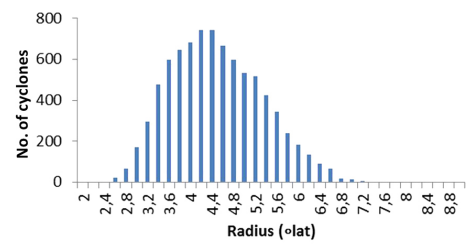

Speed Histogram

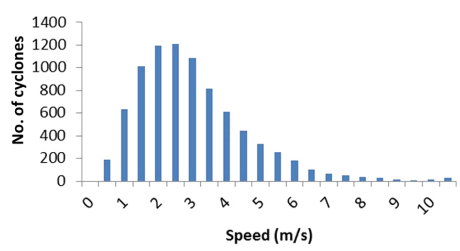

Figure 6. Histograms of the basic characteristics of the cyclone centers whose radius reach the Crete domain.

ues are in the range of $1002-1018 \mathrm{hPa}$, with a mean pressure of $1010 \mathrm{hPa}$. So, most of the cyclone systems surrounding Crete are weak and moderate according to the classification of Maheras et al. (2001).

Approximately $80 \%$ of the intensity values of the cyclonic centers extend from 0.3 to $1.1 \mathrm{hPa}^{\circ}$ lat $^{2}$ and their mean approaches $0.86 \mathrm{hPa}^{\circ}$ lat ${ }^{2}$. In addition, the majority of the cyclonic depth values are in the range of $0.4-4.6 \mathrm{hPa}$, giving a mean depth of $2.9 \mathrm{hPa}$, close enough to the $2.15-2.17 \mathrm{hPa}$ mean depth found by Flocas et al. (2010) within the eastern Mediterranean region. Also, the values extending from 3.2 to $5.4^{\circ}$ lat concern $80 \%$ of the cyclones' radius and the corresponding mean is $4.4^{\circ}$ lat. This is in great agreement with Trigo et al. (1999) who found the average cyclone radius to be approximately $4.5^{\circ}$ lat (or $500 \mathrm{~km}$ ) in the Aegean region in winter and spring. Generally, the radius of Mediterranean cyclones is considerably smaller than that of Atlantic synoptic systems which reach $18^{\circ}$ (Lionello et al., 2006). Lastly, the majority of propagation velocity values are between 0.5 and $4.5 \mathrm{~m} \mathrm{~s}^{-1}$, with a mean of $2.8 \mathrm{~m} \mathrm{~s}^{-1}$. The propagation velocity range in which most cyclones appear near in the domain includes 3.6-3.9 $\mathrm{m} \mathrm{s}^{-1}$, characterizing eastern Mediterranean cyclones according to Flocas et al. (2010).

\subsection{Cyclone-rain coincidence for Crete island: cyclone characteristics}

In this section, we give a statistical overview of the cyclone characteristics for the cyclone systems associated with precipitation events in the island of Crete. Figure 7 demonstrates pressure, intensity, depth, radius and propagation velocity of the cyclonic centers in box-and-whisker plots. The diagram of each characteristic shows the main statistical properties for every rain category ( $x$ axis) and every season (background color band). The statistical significance of these characteristics is checked pair-wise for the different rain categories and seasons, and the results are presented in detail in Tables 3 and 4, respectively. For the majority of pairs, the differences between the populations of the characteristics are found to be significant. An analysis for every cyclone feature follows, according to Fig. 7.

The pressure diagram of Fig. 7 shows pressure decrease of the cyclone centers with the increase of precipitation. The lowest pressure values are observed in spring and the highest in autumn. The distribution of autumn pressures exhibits the smallest variations and winter the largest, and this is the case for all cyclone center features. Also, for all seasons, variability is smallest for heavy rain events. According to Table 3, pressure differences are statistically significant in all rain categories except in strong-heavy events which have significant differences in pressure only in spring. Concerning the different seasons, winter strong and heavy events' pressures do not have significant differences compared to annual pressures. Table 4 shows that the differences observed between the cyclone pressures for all the other seasons are significant.

The cyclone intensity for the different seasons and rain categories is also demonstrated in Fig. 7. It appears from the graph that intense rain is associated with cyclones of greater intensity. In addition, the highest intensities are ob- 

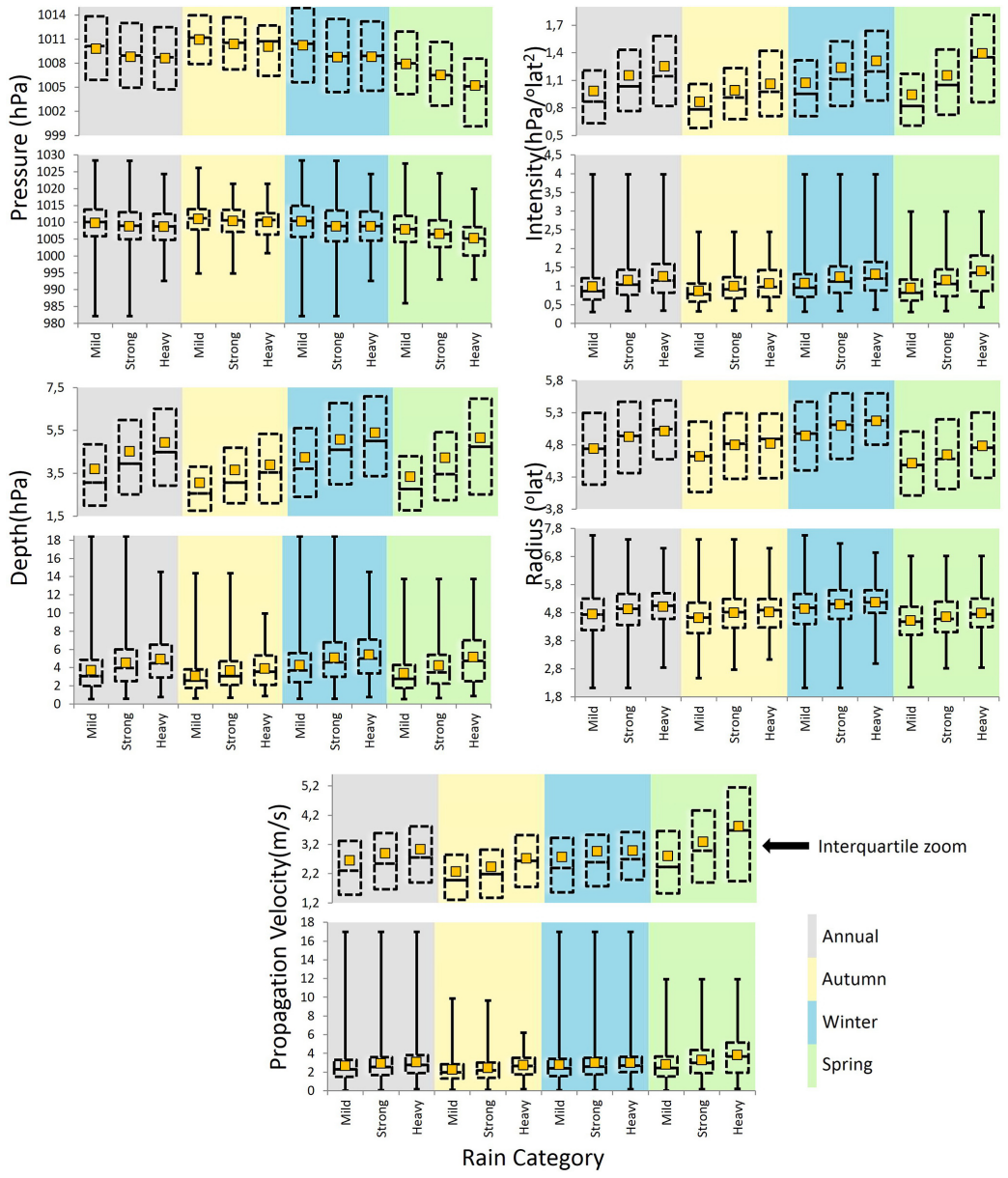

Figure 7. Seasonal and annual analysis of the basic characteristics of the cyclones triggering precipitation events over Crete island for the period 1979-2011, in box-and-whisker format.

served for winter and the lowest for autumn. Only for heavy rain events, for the majority of cases, cyclones are more intense in spring. Likewise, the depth of cyclonic centers associated with precipitation events shows an increasing magnitude with increasing rain intensity. This is expected, taking into consideration that cyclone depth is considered to be a very satisfying measure for cyclone influence (Simmonds and Keay, 2000). The values of cyclonic depth are higher in the winter period, followed by spring and autumn. Generally, both intensity and depth have statistical significant differences for the rain categories and seasons, except for a few cases which are not statistically significant. The corresponding results are presented in Tables 3 and 4.

According to Fig. 7, increasing magnitude is observed for the radius of the cyclones affecting Crete. This is more evident for mild and strong rain. The radii of cyclones associated with heavy rain have negligible differences to those associated with strong rain, especially in autumn which is also not statistically significant in contrast to the other seasons. Also, greater radius values are observed for winter cyclones, followed by autumn and spring.
The last graph of Fig. 7 shows the cyclone propagation velocity. The propagation velocity of cyclones increases with the rain intensity. Thus, greater propagation velocity is observed for heavy rain compared to the other two rain categories. Additionally, higher cyclone velocities are observed in spring compared to the other seasons. The differences of propagation velocity for the rain categories are significant according to Table 3. Also, as shown in Table 4, statistically significant differences are found for the majority of propagation velocity seasonal pairs.

The characteristics of the cyclone centers whose appearance is associated with rain events in the island of Crete are presented in Fig. 8. In particular, the first column shows the average values of the characteristics for all three rain categories and the second column shows the average value for cyclone centers associated with heavy rain events. In order to identify possible patterns and trends in cyclone characteristics, the cyclone centers are considered according to their relative position to Crete (sectors as presented in Fig. 1).

For both average and heavy rain, the lowest pressures are observed in spring, followed by winter and autumn for 
Table 3. Statistical significance results for the characteristics of "affecting" cyclones concerning the different rain categories. The statistical significant differences at $5 \%$ significant level are denoted by 1. The zero values denoted in bold font are those not significant in neither 1,5 nor $10 \%$ significant levels and zero values which were not noted are significant at $10 \%$ significant level.

\begin{tabular}{|c|c|c|c|}
\hline Season & Mild-strong & Mild-heavy & Strong-heavy \\
\hline \multicolumn{4}{|c|}{ Pressure } \\
\hline Annual & 1 & 1 & $\mathbf{0}$ \\
\hline Autumn & 1 & 1 & $\mathbf{0}$ \\
\hline Winter & 1 & 1 & $\mathbf{0}$ \\
\hline Spring & 1 & 1 & 1 \\
\hline \multicolumn{4}{|c|}{ Intensity } \\
\hline Annual & 1 & 1 & 1 \\
\hline Autumn & 1 & 1 & $\mathbf{0}$ \\
\hline Winter & 1 & 1 & 1 \\
\hline Spring & 1 & 1 & 1 \\
\hline \multicolumn{4}{|c|}{ Depth } \\
\hline Annual & 1 & 1 & 1 \\
\hline Autumn & 1 & 1 & 0 \\
\hline Winter & 1 & 1 & 1 \\
\hline Spring & 1 & 1 & 1 \\
\hline \multicolumn{4}{|c|}{ Radius } \\
\hline Annual & 1 & 1 & 1 \\
\hline Autumn & 1 & 1 & $\mathbf{0}$ \\
\hline Winter & 1 & 1 & 1 \\
\hline Spring & $\mathbf{0}$ & 1 & 0 \\
\hline \multicolumn{4}{|c|}{ Propagation velocity } \\
\hline Annual & 1 & 1 & 1 \\
\hline Autumn & 1 & 1 & 1 \\
\hline Winter & 1 & 1 & 0 \\
\hline Spring & 1 & 1 & 1 \\
\hline
\end{tabular}

all sectors. Generally, cyclones associated with heavy rain events demonstrate lower pressures than the average pressure. The different sectors have negligible variations, except for the west sector which has the greatest pressures for both average and heavy rain in autumn and the lowest pressures in spring. This is more profound in heavy rain cases. Also, the north $(\mathrm{N}, \mathrm{NE}, \mathrm{NW})$ cyclone centers have lower pressures than the south ones (S, SE, SW).

Cyclone intensity and depth seem to show similar behavior which is justified because depth is proportional to intensity (Simmonds and Keay, 2000). The lowest values are observed in autumn and the highest for winter and spring. Additionally, both intensities and depths are greater for heavy rain events. Annually, the west sector is found to have the greatest intensity and depth. Winter and spring are in agreement with this behavior, with the exception of autumn which has

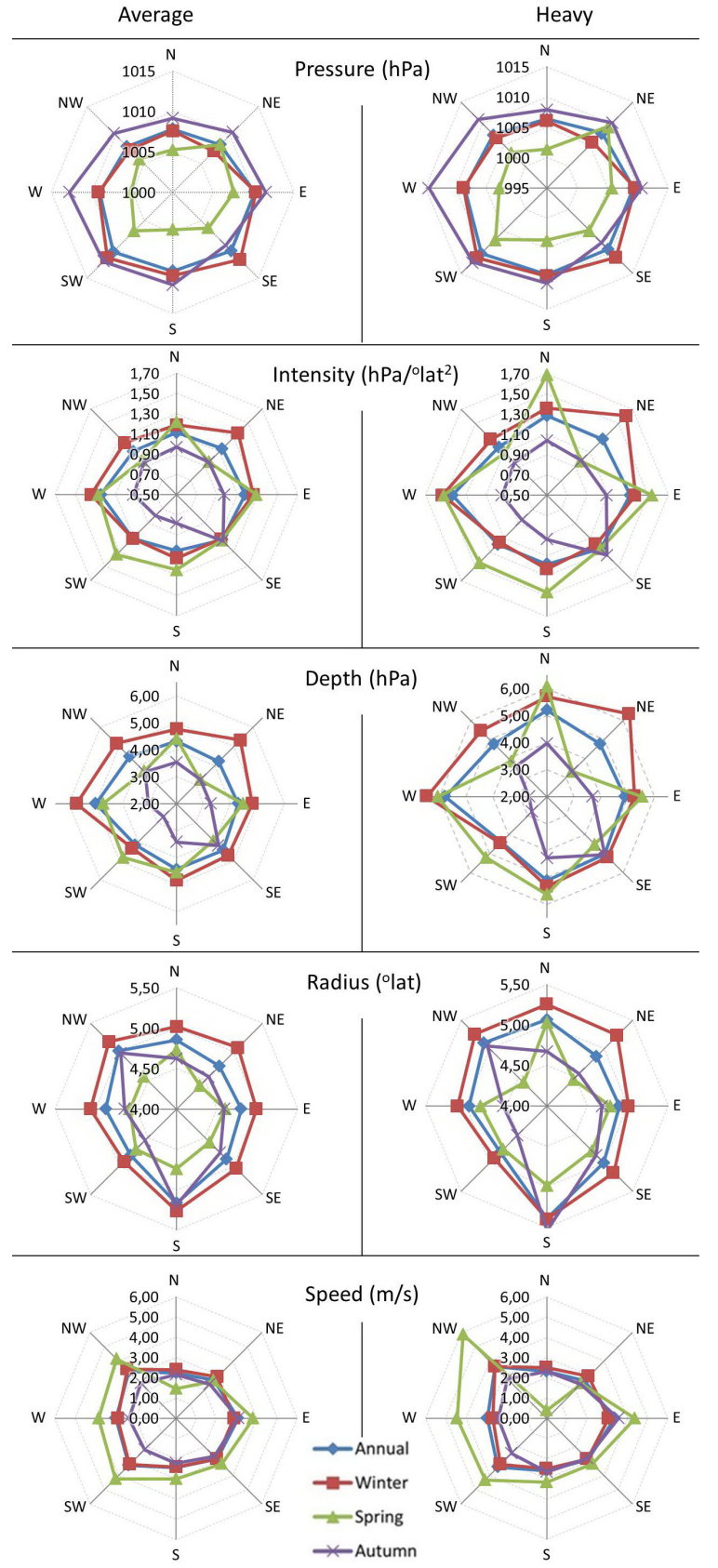

Figure 8. Seasonal and annual analysis of the basic characteristics of the cyclones triggering precipitation events over Crete island for the period 1979-2011. The left column represents the average for all rain events and the right column only represents heavy precipitation events.

its greatest values in intensity and depth for the southeast sector.

The cyclone radius is greater in winter and in most of the cases, it has greater values for heavy rain in contrast to the average. Also, its lowest values are observed in autumn (west sector) and spring (northwest and northeast sector). 
Table 4. Statistical significance results for the characteristics of "affecting" cyclones concerning the different seasons. The statistical significant differences at $5 \%$ significant level are denoted by 1 . The zero values denoted in bold font are those not significant in neither 1,5 nor $10 \%$ significant level and zero values which were not noted are significant at $10 \%$ significant level.

\begin{tabular}{|c|c|c|c|c|c|c|}
\hline Rain category & Winter-spring & Winter-autumn & Winter-annual & Spring-autumn & Sprin-annual & Autumn-annual \\
\hline \multicolumn{7}{|c|}{ Pressure } \\
\hline Mild & 1 & 1 & 1 & 1 & 1 & 1 \\
\hline Strong & 1 & 1 & 0 & 1 & 1 & 1 \\
\hline Heavy & 1 & 1 & $\mathbf{0}$ & 1 & 1 & 1 \\
\hline \multicolumn{7}{|c|}{ Intensity } \\
\hline Mild & 1 & 1 & 1 & 1 & 1 & 1 \\
\hline Strong & 1 & 1 & 1 & 1 & o & 1 \\
\hline Heavy & 0 & 1 & 0 & 1 & 1 & 1 \\
\hline \multicolumn{7}{|c|}{ Depth } \\
\hline Mild & 1 & 1 & 1 & 1 & 1 & 1 \\
\hline Strong & 1 & 1 & 1 & 1 & 1 & 1 \\
\hline Heavy & 1 & 1 & 1 & 1 & $\mathbf{0}$ & 1 \\
\hline \multicolumn{7}{|c|}{ Radius } \\
\hline Mild & 1 & 1 & 1 & 1 & 1 & 1 \\
\hline Strong & 1 & 1 & 1 & 1 & 1 & 1 \\
\hline Heavy & 1 & 1 & 1 & $\mathbf{0}$ & 1 & 1 \\
\hline \multicolumn{7}{|c|}{ Propagation velocity } \\
\hline Mild & 0 & 1 & 1 & 1 & 1 & 1 \\
\hline Strong & 1 & 1 & 0 & 1 & 1 & 1 \\
\hline Heavy & 1 & 0 & 0 & 1 & 1 & o \\
\hline
\end{tabular}

The greatest radius magnitudes for all seasons are observed in the south sector.

The last cyclone characteristic presented in Fig. 8 concerns cyclone propagation velocity which demonstrates its greatest values in spring and lowest in autumn for the majority of cases. Also, the north sector has the lowest propagation velocity values compared to the other sectors and NW, W, SW sectors have the greatest. Additionally the cyclone propagation velocity is greater for heavy rain rather than the average case.

The results depicted in Fig. 8 provide an insight into location-specific characteristics of the cyclones associated with precipitation events in Crete. In most cases, the cyclone characteristics per sector presented in Fig. 8 confirm the general behavior of the cyclone characteristics demonstrated in Fig. 7. Generally, seasonal differences among the sectors are observed as well as extreme values for heavy rain events. Concerning the defined sectors, the west sector stands out demonstrating the lowest and highest values for the majority of cyclone characteristics in spring and autumn which is more profound in heavy rain case. Also, spring cyclone centers located in the north sector are distinguished for the low pressure and propagation velocity values as well as intensity, depth and radius magnitudes which are considerably high, compared to the other sectors.

\section{Conclusions}

In this work the main characteristics of cyclones associated with precipitation events in Crete have been explored for a 30 year period (1979-2011). The identification, tracking and feature definition of the cyclones was accomplished with the aid of the Melbourne University algorithm (MS scheme). This analysis allows us to better understand the behavior of atmospheric systems related to rainfall situations introducing a step-by-step methodology for the association of cyclones with rain. In addition, although of a local nature, the study is of great interest, since Crete has a key location in the eastern Mediterranean basin.

It was found that for the majority of strong and heavy rain events, cyclones were detected nearby Crete and that the season of the greatest coincidence between rain and cyclones is spring, followed by winter and autumn. In addition, it was verified that cyclones affecting Crete mainly originate from the northwest, followed by the southwest. Passing from mild to heavy rain events, the proportional difference between the origination of the associated cyclone percentages is getting 
smaller. Also, the cyclone centers north of Crete were the main triggering mechanisms of mild and strong rain events, followed by those located in the south. This still applies for events of greater rainfall, although the difference is slighter and especially in spring, the majority of heavy rain events are caused by southern cyclone centers.

The distribution of the values of the cyclone characteristics is normal for pressure and radius and left skewed for the rest of the characteristics. Moreover, increasing or decreasing trends can be distinguished for the characteristics of the cyclones associated with rainfall. A negative trend is observed for pressure, and positive trends for intensity, depth, radius and propagation velocity with rain increase. Seasonally, spring cyclones are more prone to lower pressures and greater cyclone propagation velocity, while winter cyclones yield greater intensity, depth and radius. This behavior applies for the majority of the sectors considered around Crete, with some variations.

This study examines the characteristics of the cyclones associated with rainfall events in Crete. To the best of our knowledge, this is the first attempt to relate the characteristics of the cyclones such as pressure, depth and radius to rain intensity. Although cyclones have been extensively studied for their climatology, topology, frequency (Flocas et al., 2010; Neu et al., 2013) and also their relation to physical phenomena like rain and wind (Catto et al., 2012; Hawcroft et al., 2012), this is the first time the relationship of their characteristics to the intensity of the rain events is investigated. This methodology was recently applied for the construction of a rain prediction model (Iordanidou et al., 2014) providing information that can be valuable and supplementary for forecasting purposes. Individually or in association with additional information, the development of a basic warning system for the management and mitigation of flood events can be achieved. Further analysis of the cyclonic tracks and characteristics projected by climate models can provide valuable information for the impact of global change on the atmospheric systems in the wider eastern Mediterranean.

Acknowledgements. We thank I. Simmonds from the University of Melbourne who kindly provided the cyclone tracking algorithm. We are grateful to Helena Flocas and the members of her group from the National and Kapodistrian University of Athens for providing valuable guidance through the application process. V. Iordanidou and I. K. Tsanis were supported during the revisions by the "ARISTEIA II" Action ("REINFORCE" program) of the "Operational Education and Lifelong Learning programme" and are co-funded by the European Social Fund (ESF) and National Resources.

Edited by: G. Panegrossi

Reviewed by: three anonymous referees

\section{References}

Bartholy, J., Pongrácz, R., and Pattantyús-Ábrahám, M.: Analyzing the genesis, intensity, and tracks of western Mediterranean cyclones, Theor. Appl. Climatol., 96, 133-144, doi:10.1007/s00704-008-0082-9, 2008.

Catto, J. L., Jakob, C., Berry, G., and Nicholls, N.: Relating global precipitation to atmospheric fronts, Geophys. Res. Lett., 39, L10805, doi:10.1029/2012GL051736, 2012.

Chartzoulakis, K. and Psarras, G.: Global change effects on crop photosynthesis and production in Mediterranean: the case of Crete, Greece, Agric. Ecosyst. Environ., 106, 147-157, doi:10.1016/j.agee.2004.10.004, 2005.

Claud, C., Alhammoud, B., Funatsu, B. M., and Chaboureau, J.-P.: Mediterranean hurricanes: large-scale environment and convective and precipitating areas from satellite microwave observations, Nat. Hazards Earth Syst. Sci., 10, 2199-2213, doi:10.5194/nhess-10-2199-2010, 2010.

Flaounas, E., Raveh-Rubin, S., Wernli, H., Drobinski, P., and Bastin, S.: The dynamical structure of intense Mediterranean cyclones, Clim. Dynam., 44, 2411-2427, doi:10.1007/s00382-0142330-2, 2014.

Flocas, H. A., Simmonds, I., Kouroutzoglou, J., Keay, K., Hatzaki, M., Bricolas, V., and Asimakopoulos, D.: On Cyclonic Tracks over the Eastern Mediterranean, J. Climate, 23, 5243-5257, doi:10.1175/2010JCLI3426.1, 2010.

Gaume, E., Bain, V., Bernardara, P., Newinger, O., Barbuc, M., Bateman, A., Blaškovičová, L., Blöschl, G., Borga, M., Dumitrescu, A., Daliakopoulos, I., Garcia, J., Irimescu, A., Kohnova, S., Koutroulis, A., Marchi, L., Matreata, S., Medina, V., Preciso, E., Sempere-Torres, D., Stancalie, G., Szolgay, J., Tsanis, I., Velasco, D., and Viglione, A.: A compilation of data on European flash floods, J. Hydrol., 367, 70-78, doi:10.1016/j.jhydrol.2008.12.028, 2009.

Grillakis, M. G. and Tsanis, I. K.: Integrated flash flood analysis in ungauged watersheds, in 12th Plinius Conference on Mediterranean Storms, vol. 12, Plinius Conference Abstracts, Corfu Island Greece, p. 18, 2010.

Hawcroft, M. K., Shaffrey, L. C., Hodges, K. I., and Dacre, H. F.: How much Northern Hemisphere precipitation is associated with extratropical cyclones?, Geophys. Res. Lett., 39, L24809, doi:10.1029/2012GL053866, 2012.

Iordanidou, V., Koutroulis, A. G., and Tsanis, I. K.: A Probabilistic Rain Diagnostic Model Based on Cyclone Statistical Analysis, Adv. Meteorol., 2014, 498020, doi:10.1155/2014/498020, 2014.

Jansa, A., Buzzi, A., and Arbogast, P.: MEDEX, cyclones that produce high impact weather in the Mediterranean, available at: http://medex.inm.uib.es (last access: 18 September 2014), 2001a.

Jansa, A., Genoves, A., Picornell, M. A., Campins, J., Riosalido, R., and Carretero, O.: Western Mediterranean cyclones and heavy rain. Part 2: Statistical approach, Meteorol. Appl., 8, 43-56, doi:10.1017/S1350482701001049, 2001b.

Karagiannidis, A., Karacostas, T., Maheras, P., and Makrogiannis, T.: Trends and seasonality of extreme precipitation characteristics related to mid-latitude cyclones in Europe, Adv. Geosci., 20, 39-43, doi:10.5194/adgeo-20-39-2009, 2009.

Kouroutzoglou, J., Flocas, H. A., Keay, K., Simmonds, I., and Hatzaki, M.: Climatological aspects of explosive cyclones in the Mediterranean, Int. J. Climatol., 31, 1785-1802, doi:10.1002/joc.2203, 2011a. 
Kouroutzoglou, J., Flocas, H., Simmonds, I., Keay, K., and Hatzaki, M.: Assessing characteristics of Mediterranean explosive cyclones for different data resolution, Theor. Appl. Climatol., 105, 263-275, doi:10.1007/s00704-010-0390-8, 2011b.

Kouroutzoglou, J., Flocas, H. A., Keay, K., Simmonds, I., and Hatzaki, M.: On the vertical structure of Mediterranean explosive cyclones, Theor. Appl. Climatol., 110, 155-176, doi:10.1007/s00704-012-0620-3, 2012.

Koutroulis, A. G. and Tsanis, I. K.: A method for estimating flash flood peak discharge in a poorly gauged basin: Case study for the 13-14 January 1994 flood, Giofiros basin, Crete, Greece, J. Hydrol., 385, 150-164, doi:10.1016/j.jhydrol.2010.02.012, 2010.

Koutroulis, A. G., Tsanis, I. K., and Daliakopoulos, I. N.: Seasonality of floods and their hydrometeorologic characteristics in the island of Crete, J. Hydrol., 394, 90-100, doi:10.1016/j.jhydrol.2010.04.025, 2010.

Leonard, S. R., Turner, J., and Wal, A. Van Der: An assessment of three automatic depression tracking schemes, Meteorol. Appl., 6, 173-183, 1999.

Lim, E. and Simmonds, I.: Southern Hemisphere winter extratropical cyclone characteristics and vertical organization observed with the ERA-40 data in 1979-2001, J. Climate, 20, 2675-2690, doi:10.1175/JCLI4135.1, 2007.

Lionello, P., Bhend, J., Buzzi, A., Della-Marta, P. M., Krichak, S. O., Jansa, A., Maheras, P., Sanna, A., Trigo, I. F., and Trigo, R.: Cyclones in the Mediterranean Region: Climatology and Effects on the Environment, in: Mediterranean Climate Variability, Amsterdam, 325-372, 2006.

Maheras, P., Flocas, H. A., Patrikas, I., and Anagnostopoulou, C.: A 40 year objective climatology of surface cyclones in the Mediterranean region: spatial and temporal distribution, Int. J. Climatol., 21, 109-130, doi:10.1002/joc.599, 2001.

Marchi, L., Borga, M., Preciso, E., and Gaume, E.: Characterisation of selected extreme flash floods in Europe and implications for flood risk management, J. Hydrol., 394, 118-133, doi:10.1016/j.jhydrol.2010.07.017, 2010.

Miglietta, M. M., Laviola, S., Malvaldi, A., Conte, D., Levizzani, V., and Price, C.: Analysis of tropical-like cyclones over the Mediterranean Sea through a combined modeling and satellite approach, Geophys. Res. Lett., 40, 2400-2405, doi:10.1002/grl.50432, 2013.

Murray, R. J. and Simmonds, I.: A numerical scheme for tracking cyclone centres from digital data. Part I: development and operation of the scheme, Aust. Meteorol. Mag., 39, 155-166, 1991.

Naoum, S. and Tsanis, I. K.: Temporal and spatial variation of annual rainfall on the island of Crete, Greece, Hydrol. Process., 17, 1899-1922, doi:10.1002/hyp.1217, 2003.
Neu, U., Akperov, M. G., Bellenbaum, N., Benestad, R., Blender, R., Caballero, R., Cocozza, A., Dacre, H. F., Feng, Y., Fraedrich, K., Grieger, J., Gulev, S., Hanley, J., Hewson, T., Inatsu, M., Keay, K., Kew, S. F., Kindem, I., Leckebusch, G. C., Liberato, M. L. R., Lionello, P., Mokhov, I. I., Pinto, J. G., Raible, C. C., Reale, M., Rudeva, I., Schuster, M., Simmonds, I., Sinclair, M., Sprenger, M., Tilinina, N. D., Trigo, I. F., Ulbrich, S., U1brich, U., Wang, X. L., and Wernli, H.: IMILAST: A Community Effort to Intercompare Extratropical Cyclone Detection and Tracking Algorithms, Bull. Am. Meteorol. Soc., 94, 529-547, doi:10.1175/BAMS-D-11-00154.1, 2013.

Simmonds, I. and Keay, K.: Mean Southern Hemisphere Extratropical Cyclone Behavior in the 40-Year NCEP - NCAR Reanalysis, J. Climate, 13, 873-885, 2000.

Simmonds, I. and Murray, R. J.: Southern Extratropical Cyclone Behavior in ECMWF Analyses during the FROST Special Observing Periods, Weather Forecast., 14, 878-891, 1999.

Trigo, I. F., Davies, T. D., and Bigg, G. R.: Objective Climatology of Cyclones in the Mediterranean Region, J. Climate, 12, 16851696, 1999.

Tsanis, I. K., Koutroulis, A., Daliakopoulos, I., and Michaelides, S.: Storm analysis and precipitation distribution of the flash flood in Almyrida basin, Crete, Geophys. Res. Abstr., 10, EGU2008-A09498, EGU General Assembly 2008, Vienna, Austria, 2008.

Tsanis, I. K., Koutroulis, A. G., Flocas, H. A., Kaminari, M., Kouroutzoglou, J., and Simmonds, I.: Atmospheric circulation patterns associated with flood events in Crete, Greece, in Protection and restoration of the environment, Thessaliniki, Greece, 1842-1852, 2012.

Tsanis, I. K., Seiradakis, K. D., Daliakopoulos, I. N., Grillakis, M. G., and Koutroulis, A. G.: Assessment of GeoEye-1 stereo-pairgenerated DEM in flood mapping of an ungauged basin, J. Hydroinformatics, 16, 1-18, doi:10.2166/hydro.2013.197, 2013.

Ulbrich, U., Brucher, T., Fink, A., Leckebusch, G. C., Kruger, A., and Pinto, J. G.: The central European floods of August 2002?: Part 1 - Rainfall periods and flood development, Weather, 58, 371-377, 2003.

Ulbrich, U., Leckebusch, G. C., and Pinto, J. G.: Extra-tropical cyclones in the present and future climate: a review, Theor. Appl Climatol., 96, 117-131, doi:10.1007/s00704-008-0083-8, 2009.

Vrochidou, A.-E. K. and Tsanis, I. K.: Assessing precipitation distribution impacts on droughts on the island of Crete, Nat. Hazards Earth Syst. Sci., 12, 1159-1171, doi:10.5194/nhess-121159-2012, 2012. 